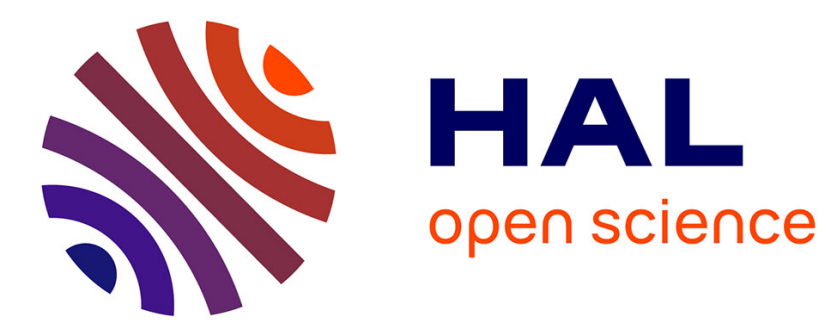

\title{
Investigation of multiple cracking in glass/epoxy 2D woven composites by vibrothermography
}

\author{
G. Bai, B. Lamboul, J.M. Roche, S. Baste
}

\section{To cite this version:}

G. Bai, B. Lamboul, J.M. Roche, S. Baste. Investigation of multiple cracking in glass/epoxy 2D woven composites by vibrothermography. The 12th International Conference on Quantitative InfraRed Thermography (QIRT 2014), Jul 2014, BORDEAUX, France. hal-01132117

\section{HAL Id: hal-01132117 \\ https://hal.science/hal-01132117}

Submitted on 16 Mar 2015

HAL is a multi-disciplinary open access archive for the deposit and dissemination of scientific research documents, whether they are published or not. The documents may come from teaching and research institutions in France or abroad, or from public or private research centers.
L'archive ouverte pluridisciplinaire HAL, est destinée au dépôt et à la diffusion de documents scientifiques de niveau recherche, publiés ou non, émanant des établissements d'enseignement et de recherche français ou étrangers, des laboratoires publics ou privés. 


\section{Investigation of multiple cracking in glass/epoxy 2D woven composites by vibrothermography}

G. Bai, B. Lamboul, J.M. Roche, S. Baste *

The 12th International Conference on

Quantitative InfraRed Thermography

(QIRT 2014)

BORDEAUX, FRANCE

7-11 juillet 2014

TP 2015-99

\section{ONERA}

THE FRENCH AEROSPACE LAB 

Investigation of multiple cracking in glass/epoxy 2D woven composites by vibrothermography.

Etude de la multi-fissuration d'un composite tissé verre/époxy par vibrothermographie.

par

G. Bai, B. Lamboul, J.M. Roche, S. Baste *

* Univ. of Bordeaux, I2M, Talence, France

\section{Résumé traduit :}

L'article fait état du développement d'une technique expérimentale de vibrothermographie sensible à l'état multi-fissuré d'un matériau composite tissé endommagé par des sollicitations de traction à des niveaux de charge croissants. L'objet de l'étude est de mettre en évidence l'effet d'une augmentation de densité de fissures sur l'auto-échauffement (moyenné ou observé plus localement) du matériau. Une corrélation entre l'échauffement et la perte de propriétés élastiques du matériau (le module de Young est ici considéré) est démontrée quantitativement. 



\title{
Investigation of multiple cracking in glass/epoxy 2D woven composites by vibrothermography
}

\author{
by G. Bai*, B. Lamboul*, J.-M. Roche* and S. Baste**
}

\begin{abstract}
* ONERA, Composite Materials and Structures Dept., 92322 Châtillon cedex, France. gabriele.bai@onera.fr
** Univ. of Bordeaux, I2M, UMR 5295, F-33400 Talence, France.
\end{abstract}

\begin{abstract}
An experimental study about the application of vibrothermography for the investigation of multiple microcracking in woven composites is here reported. The material is first damaged during tensile loading tests in order to have samples that present increasingly damaged states. The goal of the study is to apply vibrothermography to compare the sensitivity of their heating behaviour (global and local) with the crack density. A correlation between the heating and the loss of a mechanical property of the material (in this case the Young modulus) estimated with the tensile loading tests is also highlighted.
\end{abstract}

\section{Nomenclature}

$\begin{array}{clcclc}e & \text { Sample thickness } & \mathrm{mm} & \rho & \text { Density } & \mathrm{Kg} / \mathrm{m}^{3} \\ E_{T} & \text { Tangential Young modulus } & \mathrm{GPa} & C_{P} & \text { Specific heat } & \mathrm{J} / \mathrm{KgK} \\ L & \text { Sample length } & \mathrm{mm} & \left\langle q_{\text {dam }}\right\rangle_{T} & \text { Equivalent damage volumetric source } & \mathrm{W} / \mathrm{m}^{3} \\ \Delta T_{\text {bulk }} & \text { Bulk heating rate } & \mathrm{mK} / \mathrm{s} & \left\langle q_{\text {visco }}\right\rangle_{T} & \text { Equivalent viscoelastic volumetric source } & \mathrm{W} / \mathrm{m}^{3} \\ \Delta T_{\text {surf }} & \text { Surface heating rate } & \mathrm{mK} / \mathrm{s} & \Delta T & \text { Surface heating } & \mathrm{K} \\ \Delta T_{\text {dam }} & \text { Damage heating rate } & \mathrm{mK} / \mathrm{s} & \varepsilon & \text { Strain } & - \\ \Delta T_{\text {visco }} & \text { Viscoelastic heating rate } & \mathrm{mK} / \mathrm{s} & \sigma & \text { Stress } & \mathrm{MPa}\end{array}$

\section{Introduction}

Woven composite materials, also known as textile composites, are receiving a growing interest in the industry applications thanks to their better mechanical performances in comparison with the traditional composite materials [1]. Their textile nature, characterised by the presence of the warp and the weft, guarantees a high flexibility of the reinforcement which permits the creation of very complex shaped structures [2, 3]. Unfortunately, this characteristic becomes a problem for the Non Destructive Evaluation (NDE) of this kind of material. The application of the standard NDE techniques, such as active thermography or US-scan is very complicated due to the inhomogeneities of this kind of material and to the non-uniform crack orientation [4, 5]. A solution to these problems can be searched in the vibrothermography technique. Vibrothermography, also named "Sonic IR" or "thermosonics" [6], is an NDE technique by which damage (cracks, delamination and inclusions) is detected using the heat locally generated by the friction between the defects surfaces when they are put in vibration. The first applications of this technique concern the detection of cracks in metals (in particular during fatigue tests) for which the technique has shown great potentialities [7, 8, 9, 10]. More recently, this technique has found applications to composite materials for the detection of macro-cracks, as delamination, or to evaluate the inhomogeneities in bonding joints $[11,12]$. Other applications concern the study of corrosion [13] or the inspection of the welds between different materials [14].

As Renshaw et al. report [15], the heat generation is a consequence of three phenomena: friction between crack surfaces, viscoelasticity and plasticity. In particular, the first one is considered as the principal source of heat generation. Some models based on the crack nature (friction coefficient, roughness...) have been developed for the estimation of the heating generated [16], but the link with the crack geometry is still complicated [11]. The contribution of the viscoelastic properties can be negligible for metals, but it can be very important for polymeric materials (like the materials analysed in this paper) [17]. Finally, the heat generation caused by plasticity can be considered to be a consequence of the friction or, to a lesser extent, of crack propagation [18]. This contribution can be negligible if the excitation stress is less than $40 \%$ of the fatigue limit of the material [8]. Some models can estimate this vibrational stress knowing the mechanical properties of the material $[19,20,21]$.

Most of these works here mentioned aim at detecting macro-cracks (with a characteristic length of some centimetres) which is not the goal of this paper. This study focuses on the application of vibrothermography to a microcracking damaged material (characteristic length of some micrometers). The goal is not the direct detection of each single crack, but to find a technique that is sensitive to a damage which is supposed to be homogeneously diffuse in terms of crack density. After the presentation of the experimental set-up, the results of the tests phase are reported. First, the results of the tensile loading tests are discussed followed by the results of the vibrothermography tests. Some conclusions and observations are reported in the final part of this paper. 


\section{Experimental approach}

The studied material is a 4 plies, $1.6 \mathrm{~mm}$ thick glass/epoxy 2D woven composite. Three samples of this material $(25 \times 185 \mathrm{~mm})$ are damaged by tensile tests stopped at different loads, in order to obtain different damage states. The tensile testing machine is monitored with image correlation cameras, optical microscope and acoustic emission sensors in order to collect different data from the tests and define each damage level of the material. In particular, the first sample is monitored with the acoustic emission, up to its failure (280 MPa). The cumulative acoustic energy is then used to select the other two damage levels: one is a close-to-failure damage level at $250 \mathrm{MPa}$, and the other one is a low damage level at $190 \mathrm{MPa}$. The microscope acquires images of the cross-section in order to estimate the damage state of each sample in terms of a crack density. The image correlation cameras along with the machine force signal permit to extrapolate the stress-strain variation of the material that can be used to calculate the variation of the Young modulus during the tests. All these quantities can be correlated between each other in order to estimate how the damage state of the material could influence the mechanical properties of the material, as reported in the results section of this paper.

In a second phase, vibrothermography tests are performed to study the influence of the damage on the thermal behaviour of the material when it is excited at a fixed frequency. The vibrothermography testing set-up, as illustrated in figure 1 is composed of a fixed structure where the sample can be positioned to obtain different fixation conditions. A symmetric configuration is recommended in order to be sensitive only to the damage state of the material. To optimise the vibration behaviour of the material, a fixed-fixed condition is chosen in this study. The samples are excited by a piezoelectric vibration generator (Meggitt Wilcoxon Research model F7) with a usable frequency range of 500-20,000 $\mathrm{Hz}$. Different excitation frequencies are studied, but only the results for a frequency of $5 \mathrm{kHz}$ are reported here. This frequency is close to a resonant frequency of the samples that can guarantee the best results in terms of temperature variation as reported in [22, 23, 24]. Thermal images are acquired by an infrared camera (FLIR X6540) during 180 seconds at a $50 \mathrm{~Hz}$ frequency with an integration time of $3000 \mu \mathrm{s}$ (to obtain the necessary resolution of above some tenths of a degree) [25].

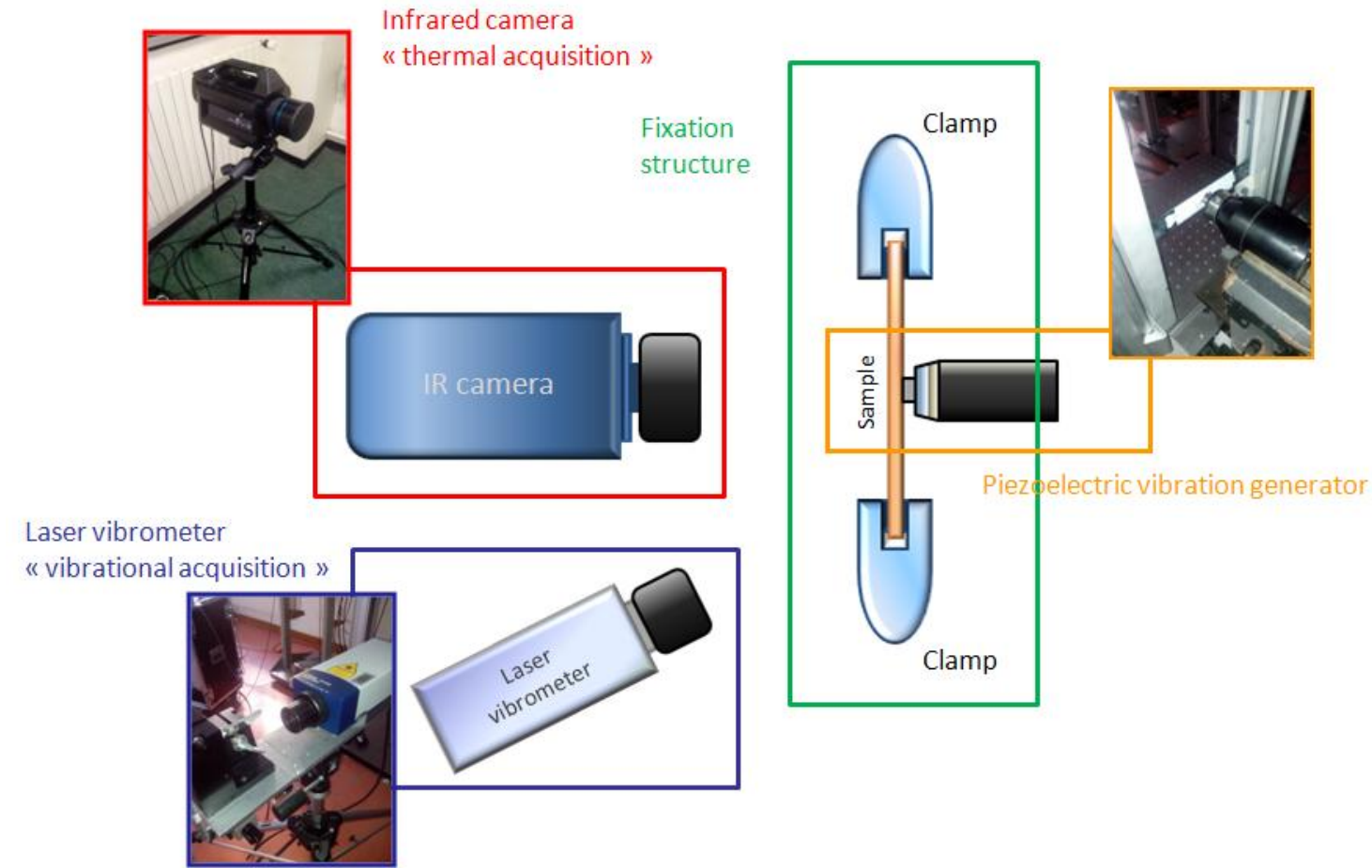

Fig. 1. Experimental setup for vibrothermography.

To insure the best reproducibility of the vibrothermography tests, different parameters that can influence the tests are taken into account. As reported in [26, 27], the most important factors are the coupling between the exciter and the sample, and the sample fixation conditions. As mentioned in [28, 29], a coupling material can be essential to obtain better results. In fact, a permanent contact with the shaker avoids all the phenomena connected to the non-linearities of the coupling. During this work, a double-sided bonding tape is used to introduce the perfect coupling between the exciter head and the sample surface that can guarantee the reproducibility of the tests. The same tightening fixation torque at both of the extremities of the samples also permits a symmetrical initial condition of the sample. Every possible initial thermal gradient that could be noticed between the samples and the fixation structure will not influence the final results because only temperature variations are studied (and so all the initials inhomogeneities are eliminated by subtraction). 


\section{Results}

The first part of this section is dedicated to the results of the tensile loading tests. For each sample, an observation of micro-cracking by microscope is performed to evaluate an equivalent crack length and a crack density to characterise the damage level. The tangential elastic modulus variation is then estimated and correlated with the crack density of the samples. The second part concerns the analysis of the vibrothermography tests. A comparison between damaged and undamaged states of the material is reported to study the influence of cracks in the thermal behaviour of the material; in particular, a global and a local analysis are performed. A correlation between the damaged conditions and the heating velocities of the samples is reported.

\subsection{Tensile tests results}

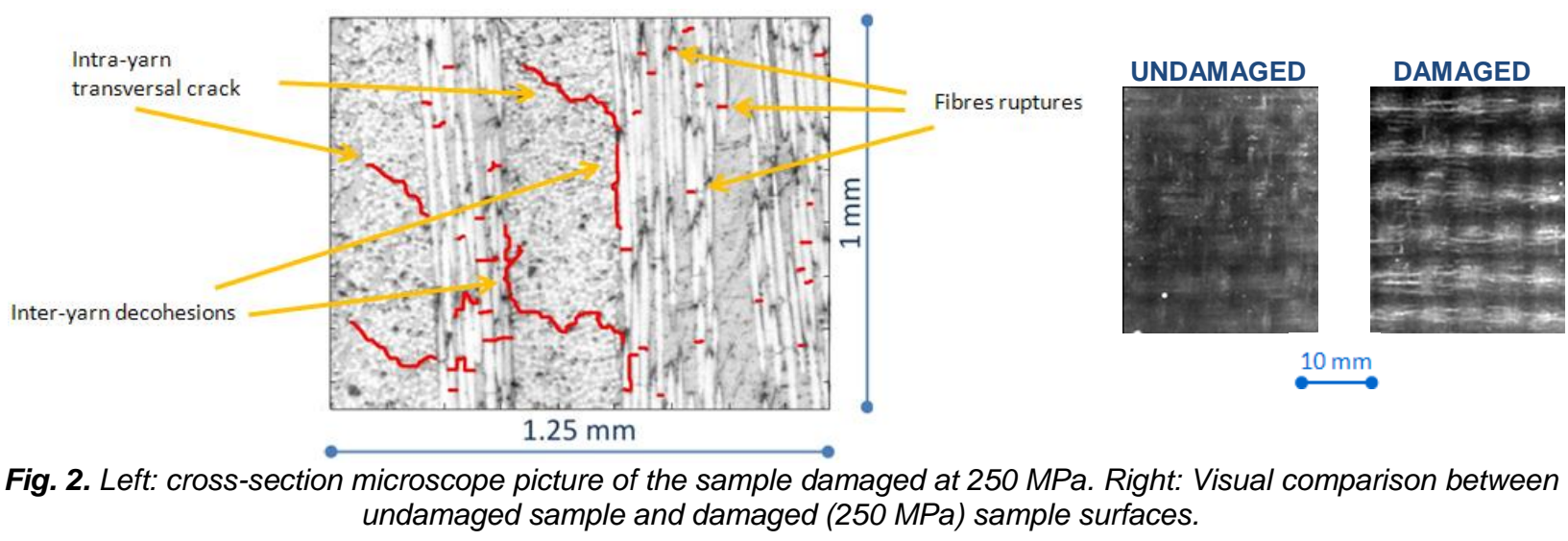

The first result reported here is a study of the typology of the damage generated during the tensile loading tests. Figure 2 (left) shows a zoomed area of a cross-section microscope picture for a sample damaged at $250 \mathrm{MPa}$ on which it is possible to identify each kind of damage. Basically, two different families of crack can be defined: fibres ruptures, with a characteristic dimension of $25 \mu \mathrm{m}$, diffuse and homogeneous in all the material, and intra/inter-yarn decohesions that have a medium dimension of $250 \mu \mathrm{m}$ and that are present locally. Figure 2 (right) also shows two images that make able to evaluate by naked eye the presence of the multiple cracking in the material in comparison with an undamaged sample. It can be noted that the damage is present along the entire width of the sample and not concentrated only at its edges. This consideration enables to make the hypothesis that the damage observed by microscopy on the cross-section is representative of the global damage condition of the sample. This hypothesis supports the introduction of a parameter that can indicate the damage level of each sample, named crack density $(\beta)$ that is defined in Eq. (1)

$$
\beta=\frac{\int_{0}^{L} L_{c}^{e q} d x}{e L}
$$

where $e$ is the thickness of the sample, $L$ its length and $L_{C}^{e q}$ (equivalent crack length) is the sum of the lengths of each crack detected by microscopy as reported in figure 3 .

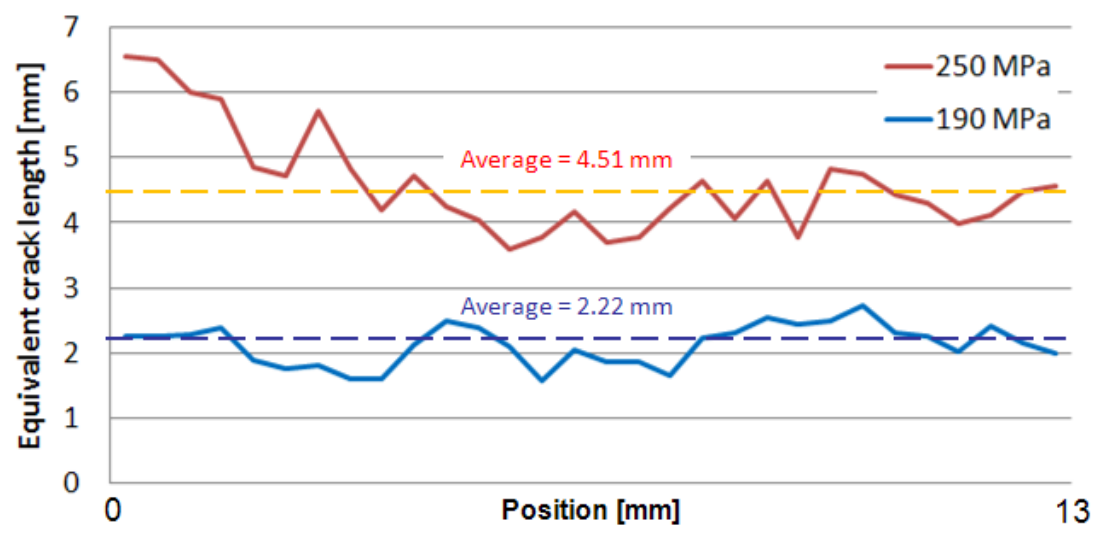

Fig. 3. Estimation of the equivalent crack length $L_{C}^{e q}$ for the damaged samples along the length of samples in the accessible field acquired by microscopic observation. 
The spatial repartition of $L_{C}^{e q}$ along the samples damaged at $190 \mathrm{MPa}$ and $250 \mathrm{MPa}$ is reported in figure 3. It is important to notice that the sample loaded at $190 \mathrm{MPa}$ is homogeneously damaged; unlike the second sample that presents a slight asymmetry. For each sample, the estimated average $L_{C}^{e q}$ is indicated. The value of the crack density estimated for each sample is reported in table 1. It is checked that the sample damaged at $250 \mathrm{MPa}$ has a doubled crack density compared to the sample loaded at $190 \mathrm{MPa}$.

Table 1. Crack density estimation

\begin{tabular}{|c|c|}
\hline Sample load $[\mathrm{MPa}]$ & Crack density $\left[\mathrm{mm}^{-1}\right]$ \\
\hline 190 & 0.34 \\
\hline 250 & 0.69 \\
\hline
\end{tabular}

The data of the image correlation cameras enable to determine the stress-strain curves for each sample and to compare them as reported in figure 4.

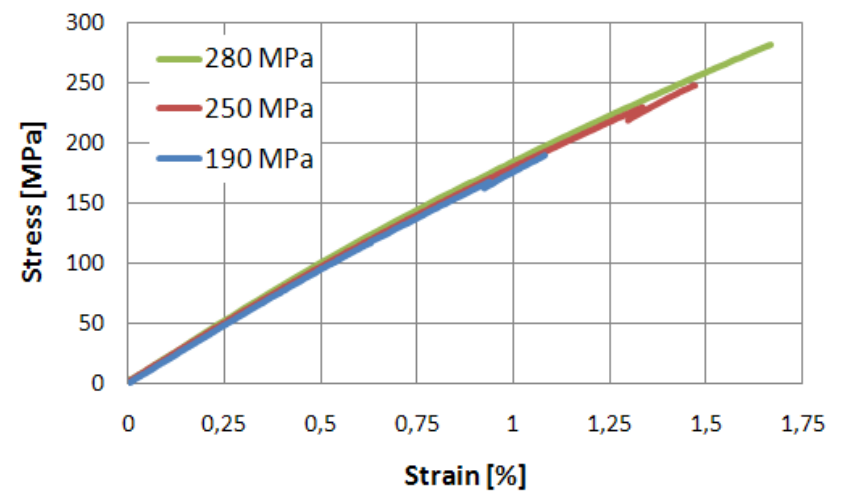

Fig. 4. Stress-strain curves for the three samples.

As observed in figure 4, the three curves have a similar behaviour which demonstrates that the considered samples are representative of the material. For each sample, it is possible to estimate the tangential Young modulus $E_{T}$ at the beginning and at the end of the tensile test (figure 5) in order to calculate its variation. This parameter can be compared with the crack density of the sample, as reported in figure 6 , in which a linear trend of these two parameters is observed.
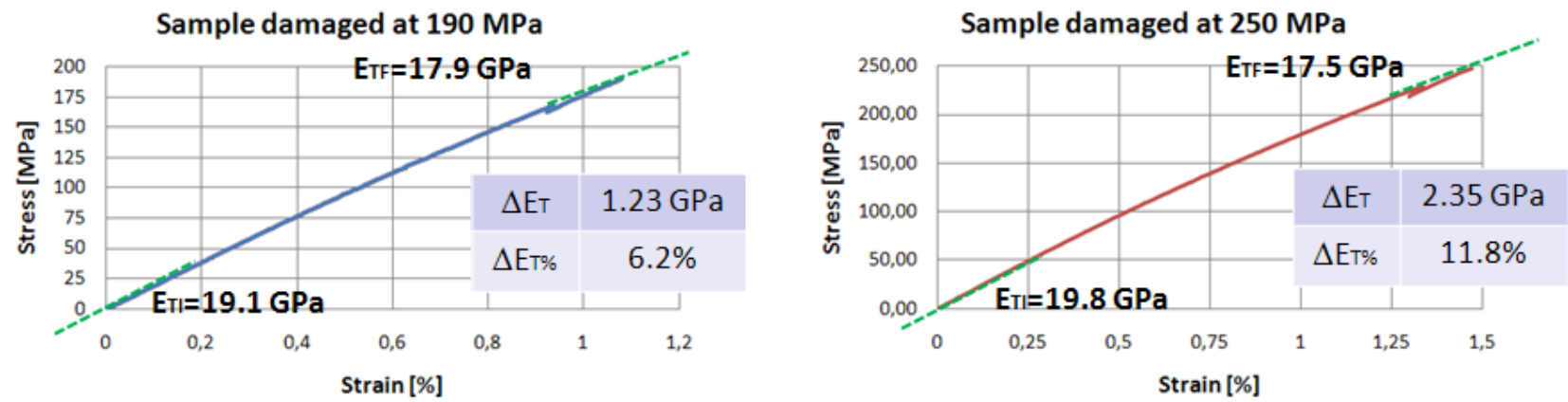

Fig. 5. Estimation of the Young modulus variation.

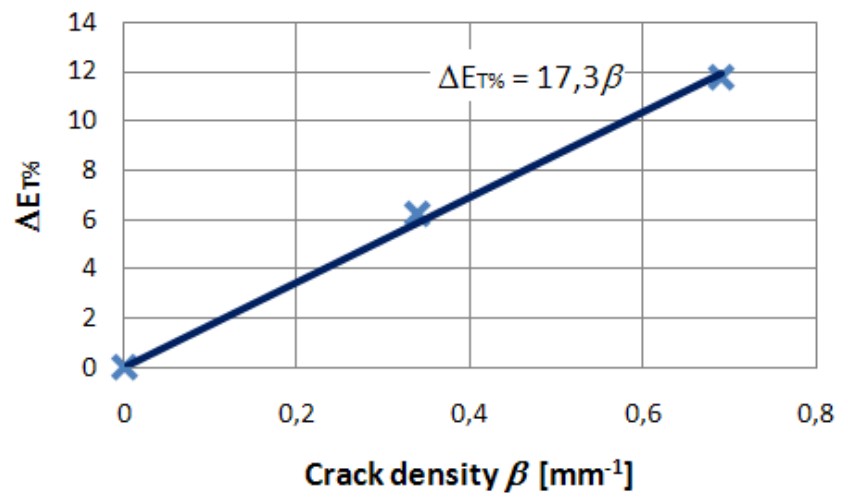

Fig. 6. Correlation between the crack density $(\boldsymbol{\beta})$ and the Young modulus variation. 


\subsection{Vibrothermography results}

In this section, the results of the vibrothermography tests are reported. The first analysis that can be conducted is to observe the thermal behaviour of the surface of the sample as function of the damage level. Two parameters can be studied: the average heating of the surface (figure 7) and the standard deviation of the measures (figure 8). In particular, figure 7 shows that the average heating of the samples depends on the damage level of the material: the more damaged the sample is, the higher the final heating is. A second observation concerns the behaviour of the undamaged sample that presents a temperature variation during the excitation. This heating cannot be created by friction of cracks in the material (it is undamaged), but it is a consequence of the viscoelastic nature of the material, as also observed in [30].

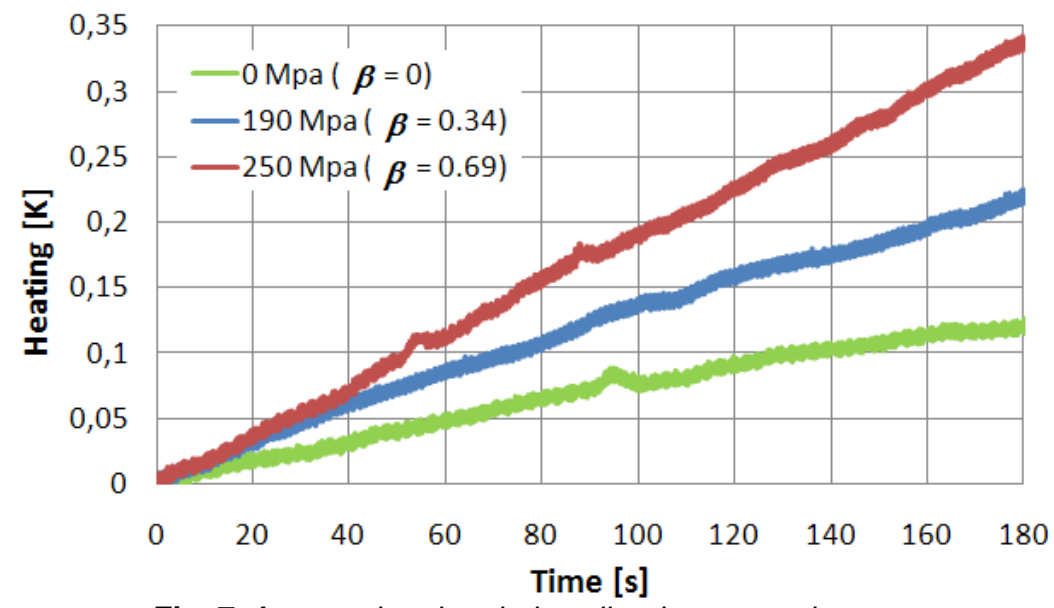

Fig. 7. Average heating during vibrothermography tests

These results demonstrate that the contributions to the heating are cracks frictions and viscoelasticity. A simple thermal model can be introduced to correlate these quantities with the heating rate of the sample, as reported in Eq. (2),

$$
\rho C_{P} \Delta T_{\text {bulk }}=\rho C_{P} \Delta \dot{T}_{\text {surf }}=\left\langle q_{\text {dam }}\right\rangle_{T}+\left\langle q_{\text {visco }}\right\rangle_{T}
$$

where $\left\langle q_{\text {dam }}\right\rangle_{T}$ and $\left\langle q_{v i s c o}\right\rangle_{T}$ are the equivalent constant volumic heat sources (averaged over a period of the excitation frequency) generated by damage and viscoelasticity, respectively; $\rho$ is the material density and $C_{P}$ is the specific heat. With the hypothesis that the heat transfers by conduction and convection are neglected, the equivalence between surface heating rate $\Delta \dot{T}_{\text {surf }}$ and bulk heating rate $\Delta T_{\text {bulk }}$ can be assumed. The quasi-linearity of the heating observed in figure 7 indicates that the sources terms introduced in the model (Eq. 2) may be considered as constants during the excitation time. This makes it possible to introduce two new parameters named damage heating rate $\Delta T_{\text {dam }}$ and viscoelastic heating rate $\Delta T_{\text {visco }}$ as defined in Eq. (3)

$$
\dot{\Delta T_{\text {surf }}}=\frac{\left\langle q_{\text {dam }}\right\rangle_{T}}{\rho C_{P}}+\frac{\left\langle q_{v i s c o}\right\rangle_{T}}{\rho C_{P}}=\dot{\Delta T_{\text {dam }}}+\dot{\Delta T_{\text {visco }}}
$$

With the hypothesis that the viscoelastic heating rate $\Delta T_{\text {visco }}$ is the same for all the samples (it is independent of the damage level of the material), the contribution of damage to the heating rate of the sample $\Delta T_{\text {dam }}$ can be estimated by subtraction from experiments on the undamaged sample. The values computed from linear regression for each sample are indicated in table 2.

Table 2. Heating rates estimated: global and damage heating

\begin{tabular}{|c|c|c|}
\hline Sample load $[\mathrm{MPa}]$ & $\Delta T_{\text {surf }}[\mathrm{mK} / \mathrm{s}]$ & $\Delta T_{\text {dam }}[\mathrm{mK} / \mathrm{s}]$ \\
\hline 0 & 0.7 & 0 \\
\hline 190 & 1.3 & 0.6 \\
\hline 250 & 1.9 & 1.2 \\
\hline
\end{tabular}

Figure 8 shows the time evolution of the standard deviation for the three samples. The growth of the standard deviation indicates that the heating of the material is not spatially homogeneous, so the source terms in Eq. (2) are dependent on space coordinates (by definition, a uniform heating would not influence the standard deviation). Then, the absence of the spurious heating peaks that it is possible to observe in the average heating of figure 7 (for example between $90 \mathrm{~s}$ and $100 \mathrm{~s}$ for the undamaged sample) indicates that these discontinuities are a global phenomenon that influences the entire sample and are a consequence of some external perturbations. Finally, the initial standard deviation (at $t=0 \mathrm{~s}$ ) is an indicator of the thermal noise level (at the initial time, the vibrothermographic effect due to the friction between cracks is null), and is similar for each test. 


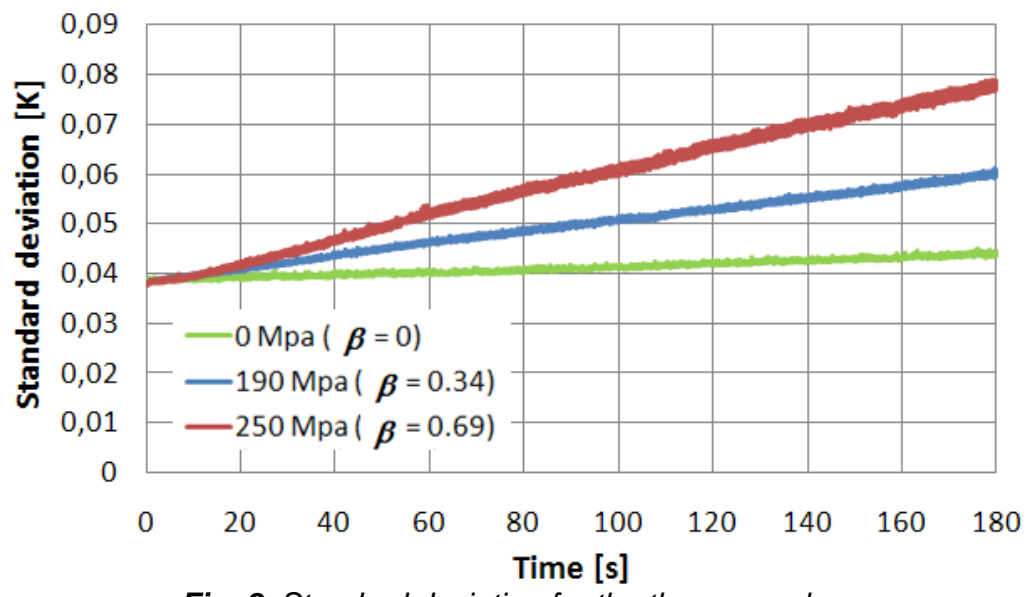

Fig. 8. Standard deviation for the three samples.

The thermal images, as those reported in figure 9, qualitatively show the heating behaviour of the sample damaged at $250 \mathrm{MPa}$. In the image are present the alternated zones with localised heating anticipated by the analysis of the standard deviation. To understand the nature of the formation of these zones, figure 10 shows a correlation between the heating of the sample and the squared out-of-plane velocity amplitude acquired thanks to a Laser vibrometer. The spatial correlation observed between normalised heating and normalised vibration velocity suggests that the heating is maximal at the maximum vibration of the sample, in agreement with previous results from the literature [30]. The maximum heating is in correspondence with the exciter position in the middle of the sample (as shown in figure 9). Heating and velocity in this region are imposed by the exciter dynamics. The asymmetrical heating that can be identified on figure 9 can be explained by the fact that the sample presents a damage condition that it is not homogeneous in the material, as demonstrated by the equivalent crack length $L_{C}^{e q}$ in figure 3 . In particular, the most damaged part of the sample generates a higher heating level.
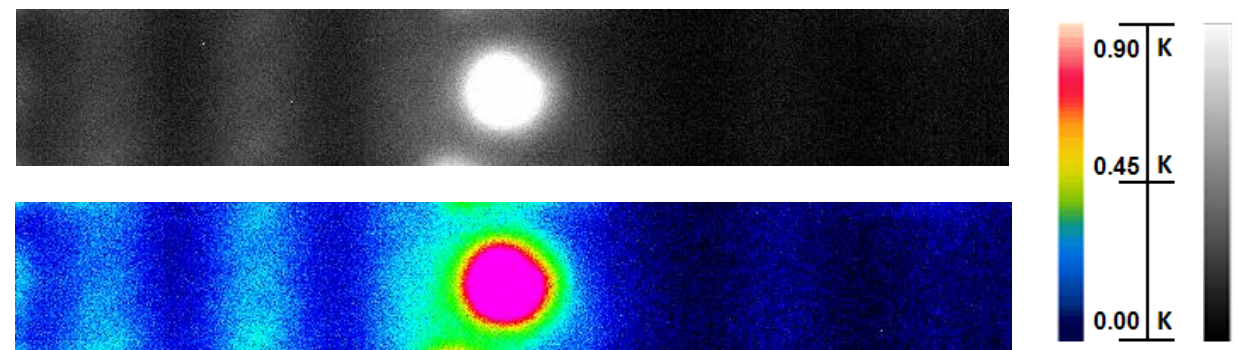

Fig. 9. Thermal image (heating) of the sample damaged at $250 \mathrm{MPa}$ (black \& white and colours).

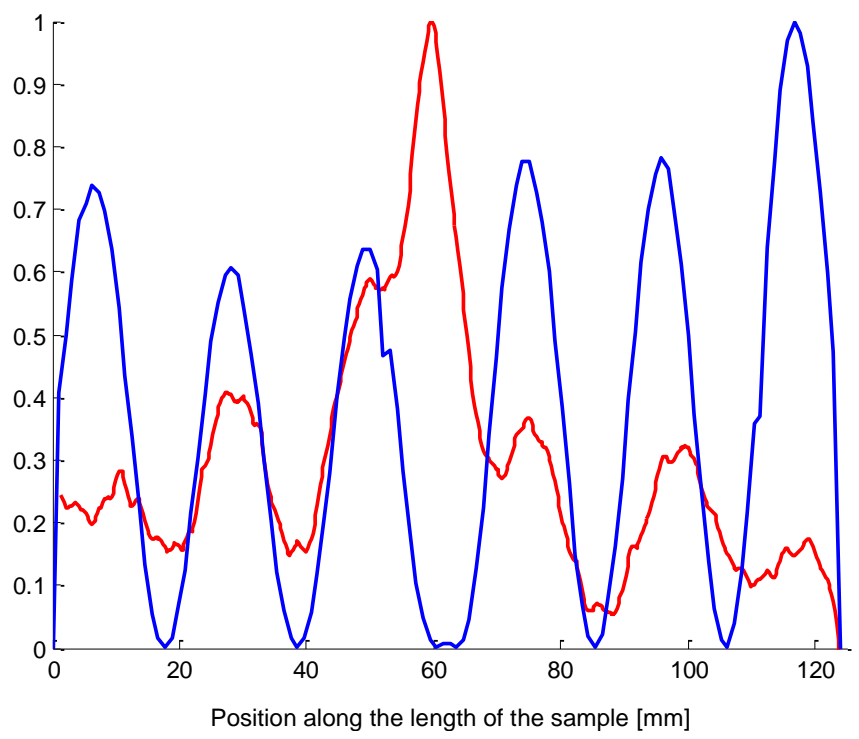

Fig. 10. Spatial correlation between the normalised heating (red) and the normalised vibrational velocity (blue). 
A local study of the heating of these zones can be achieved by looking at the temperature variations for each zone as reported in figure 11. In particular, an alternation of zones with high heating (odd numbered) with zones of lower heating (even numbered) can be observed. The zones with lower heating have a very similar behaviour; however, for the other zones the heating depends on the position of the excitation point (the closer the zone is to the centre of the sample the higher the total heating is). An explanation for this phenomenon is yet under study.
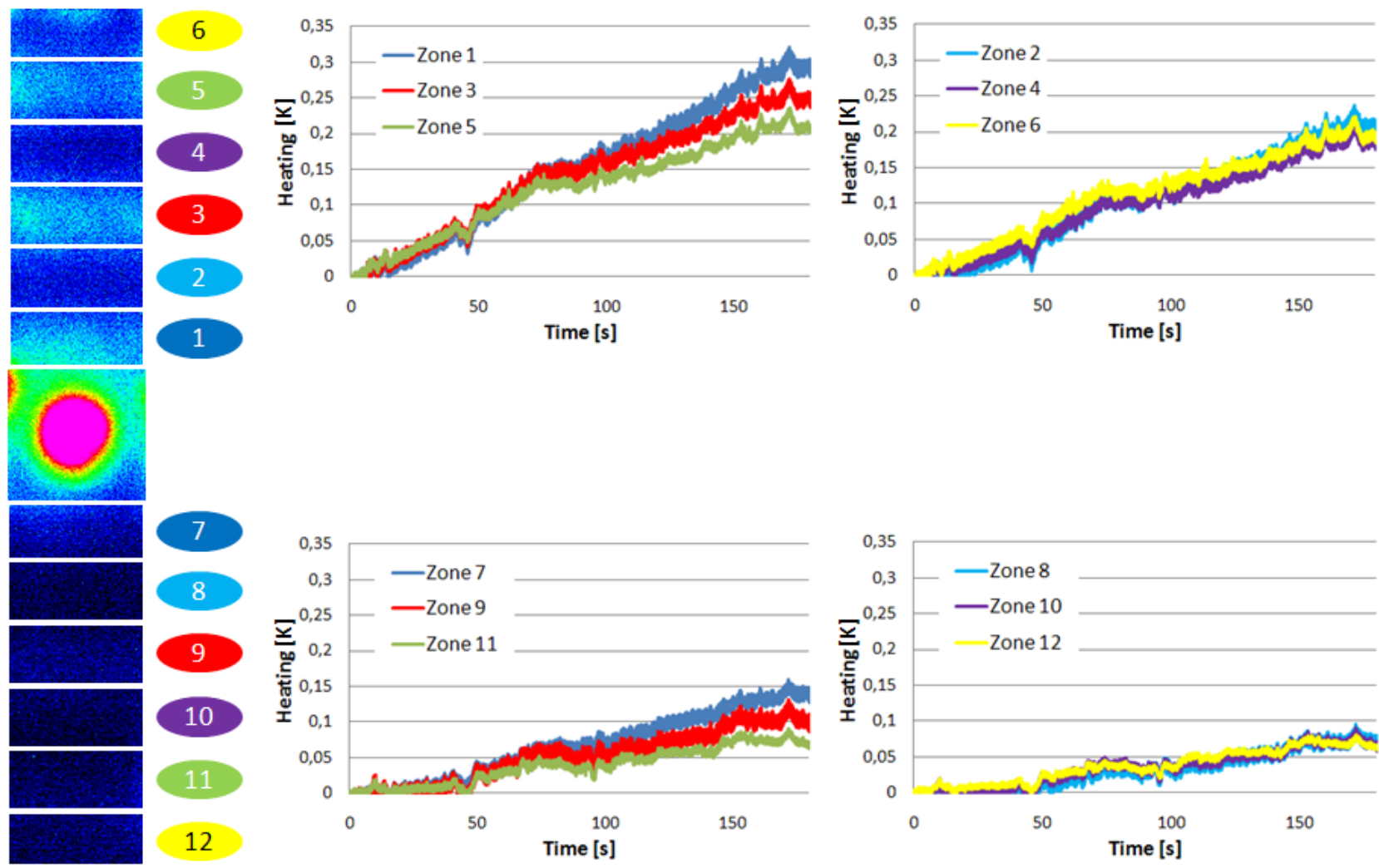

Fig. 11. Thermograms of the localised zones

A correlation between the damage heating rate $\Delta T_{d a m}$ and the damaged conditions of the sample (characterised by the crack density $\beta$ ) and the loss of a mechanical property are reported, respectively, in figure 12.a and 12.b. A linear correlation trend between these parameters can be observed and the two corresponding coefficients that can characterise the material studied in this work can be estimated.
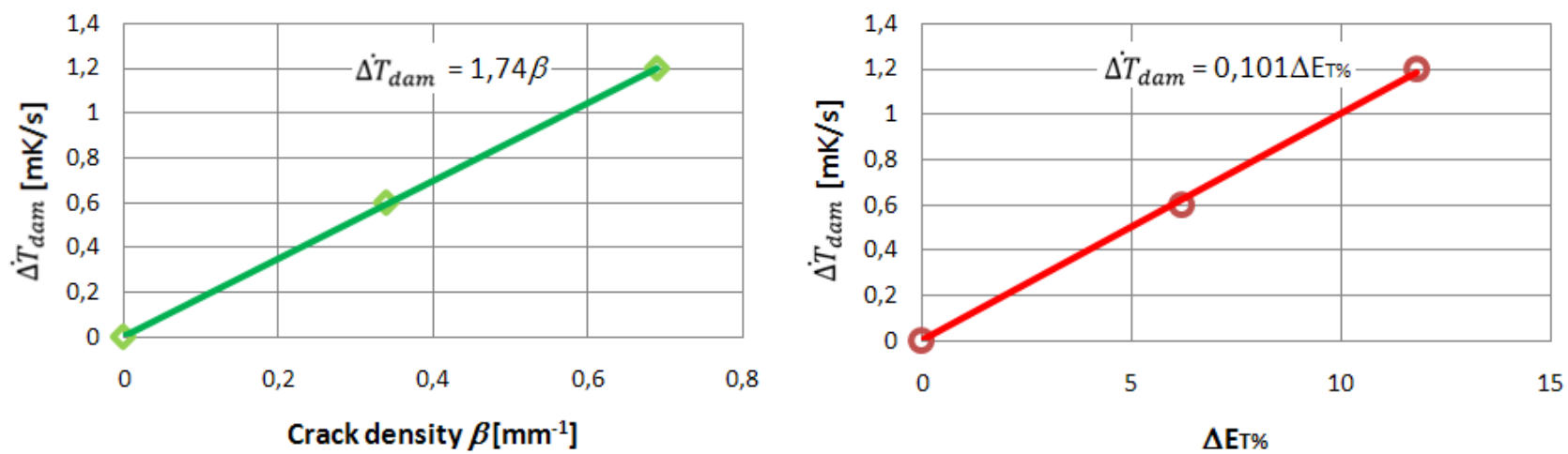

Fig. 12. A) Correlation between vibrothermographic heating velocity and: the crack density (A) and the Young modulus variation $(B)$ 


\section{Conclusions}

Table 3. Samples results

\begin{tabular}{|c|c|c|}
\hline$\sigma$ & $190 \mathrm{MPa}$ & $250 \mathrm{MPa}$ \\
\hline$\varepsilon$ & $1.08 \%$ & $1.47 \%$ \\
\hline$\Delta E_{T}$ & $6.2 \%$ & $11.8 \%$ \\
\hline$\beta$ & $0.34 \mathrm{~mm}^{-1}$ & $0.69 \mathrm{~mm}^{-1}$ \\
\hline$\dot{T}_{\text {dam }}$ & $0.6 \mathrm{mK} / \mathrm{s}$ & $1.2 \mathrm{mK} / \mathrm{s}$ \\
\hline Standard deviation & $0.06 \mathrm{~K}$ & $0.08 \mathrm{~K}$ \\
\hline
\end{tabular}

In table 3 are reported the most important results of this study in order to compare the different parameters. In conclusion this work has demonstrated that:

- $\quad$ The studied material presents a growing damage level with the loading condition that it is quantifiable by a crack density parameter.

- The global heating of the sample is a function of the damage level of the material.

- The contribution due to the viscoelastic properties of the material is identified and quantified using the undamaged sample.

- The study of the standard deviation put in evidence that the heating of the material is not uniform; there is the formation of some alternated zones visible by the thermal images. The local heating of the material is a function of the vibrational mode of the sample.

- The global heating rate of the material can be correlated with the loss of a mechanical property and the damage levels of the material. A linear correlation trend was observed in this study.

\section{REFERENCES}

[1] Lomov, Huysmans, Luo, Parnas, Prodromou, Verpoest, Phelan, "Textile composite: modelling strategies", Composites: Part A 32 (2001) 1379 - 1394.

[2] Mouritz, Bannister, Falzon, Leong, "Review of applications for advanced three-dimensional fibre textile composites." Composites: Part A (1999) 1444-1461.

[3] Brandt, Drechsler, Arendts, "Mechanical performance of composites based on various three-dimensional woven-fibre preform", Composites science and technology 56 (1996), 381-386.

[4] Roche, Balageas, Lamboul, Bai, Passilly, Mavel, Grail, "Passive and active thermography for in situ damage monitoring in woven composites during mechanical testing", QNDE 2012, Denver.

[5] Lamboul, Bai, Roche, Grail, "Estimation of elastic properties and damage monitoring in 2D woven composites using Lamb waves", NDCM-XIII 2013, Le Mans.

[6] Morbidini, Cawley, Barden, Almond, Duffour, "Prediction of the thermosonic signal from fatigue crack in metals using vibration damping measurements", journal of Applied Physics, 2006.

[7] $\mathrm{Wu}$, et al., "Nondestructive inspection of turbine blades with lock-in thermography", Material Science forum, 1996.

[8] Chen, Kephart, Lick, Riddell, "Crack growth induced by sonic IR inspection", Nondestructive Testing and Evaluation, 2007Reifsnider, Henneke, Stinchcomb, "The mechanics of vibrothermography", Mechanics of nondestructive testing, 1980.

[9] Meyendorf, Rosner, Kramb, Sathish, "Thermo-acoustic fatigue characterization", Ultrasonic 40, 2002.

[10] Favro, Thomas, Han, Ouyang, Newaz, Gentile, "Sonic infrared imaging of fatigue cracks", International journal of fatigue, 2001.

[11] Renshaw, Holland, Thompson, "Measurement of crack opening stresses and crack closure stress profiles from heat generation in vibrating cracks", Applied Physics letters, 2008.

[12] Renshaw, Holland, Thompson, "The effect of crack closure on heat generation in vibrothermography", Review of progress in quantitative nondestructive evaluation, 2009.

[13] Zweschper, Dillenz, Busse, "Ultrasound lock-in thermography - A defect-selective NDT method for the inspection of aerospace components.", Non-Destructive Testing and Condition Monitoring, 2001.

[14] Han, et al., "Sonic infrared imaging NDE", Proceedings of SPIE, 2005.

[15] Renshaw, Chen, Holland, Thompson, «The sources of heat generation in vibrothermography », NDT\&E International, 2011.

[16] Holland, Uhl, Ouyang, Bantel, Li, Meeker, Lively, Brasche, Eisenmann, "Quantifying the vibrothermographic effect", NDT\&E International, 2011.

[17] Mian, Han, Islam, Newaz, "Fatigue damage detection in graphite/epoxy composites using sonic infrared imaging technique", Composite Science and Technology, 2004. 
[18] Homma, Rothenfusser, Baumann, Shannon, "Study of the heat generation mechanism in acoustic thermography", Review of progress in quantitative nondestructive evaluation, 2006.

[19] Elmore, Heald, "Physics of waves", Dover pubblications, 1985.

[20] Renshaw, Holland, "Full-field vibration measurement for vibrothermography", Review of progress in quantitative NDE conference, 2007.

[21] Holland, Renshaw, Roberts, "Measurement of dynamic full-field internal stresses through surface laser Doppler vibrometry", Applied Physics letters 91, 2007.

[22] Montanini, Freni, "Investigation of heat generation sources in sonic infrared thermography using laser Doppler vibrometry", QIRT 2012.

[23] Zhang, Holland, "Frequency dependence of vibrothermography", Journal of NDE.

[24] Zhang, Holland, "Dependence of vibrothermographic heating on shear versus normal loading", NDT\&E International.

[25] Thesa user Manual, Flir.

[26] Shepard, Ahmed, Lhota, "Experimental considerations in vibrothermography", Thermosense XXVI vol. 5405, 2004

[27] Perez, Davis, "Optimizing the thermosonics signal”, Review of Quantitative Nondestructive Evaluation, 2003

[28] Demy, Golinval, Simon, "Détection d'endommagement de structures en matériaux composites CFRP par vibrothermographie".

[29] Han, Li, Zeng, Favro, Thomas, « Acoustic chaos and sonic infrared imaging », Applied Physics Letters, vol. 81, n17, 3188-3190, 2002.

[30] Hosten, Biateau, Bacon, Pradère, Batsale, Méziane, "Sonothermography in composite materials: Finite elements modelling and experimental validation”, NDT\&E international 51, 120-126, 2012. 




\section{ONERA}

BP 72 - 29 avenue de la Division Leclerc - 92322 CHATILLON CEDEX - Tél. : +33 146734040 - Fax : +33 146734141

w w w. onera.f r 